\title{
ENTEROGENOUS CYSTS OF ILEUM
}

\author{
BY \\ J. L. PINNIGER, D.M., M.R.C.P. \\ Lecturer in Pathology, St. Thomas's Hospital Medical School, London
}

A description is given below of a male infant having enterogenous cysts of the ileum adjacent to the ileocaecal valve. It seems worth while to add this case to those few already described in order to emphasize that enterogenous cysts in this region are a not too rare cause of acute intestinal obstruction in the young, curable by appropriate surgery. In this case the initial symptoms and signs were misleading as to diagnosis, and when those of acute obstruction eventually supervened the child was never in good enough condition for operation.

\section{Case History}

A male child, three weeks old, was admitted to hospital on April 21, 1945, on account of the sudden onset of vomiting three days previously. The vomiting had persisted since, and the child was beginning to lose weight. The vomits, which occurred after every feed, were large and moderately forceful. The child had produced two or three normal stools each day up to the time of admission, the last one just before admission being slightly green.

Condition on admission. Examination of the child showed evidence of slight dehydration. No mass or peristalsis could be observed in the abdomen and there were no other abnormal physical signs. The temperature and pulse were normal. A diagnosis of gastro-enteritis was made, and the child was put on to one-third strength Cow and Gate feeds and intermittent subcutaneous saline therapy.

Progress. For the next four weeks the child's condition remained more or less stationary. He continued to vomit up to four times daily and his bowels were opened up to five times. His weight fluctuated between $8 \mathrm{lb}$. $4 \mathrm{oz}$. and $8 \mathrm{lb}$. $11 \mathrm{oz}$. Towards the end of the period the dehydration became more marked and subcutaneous saline was given more frequently. On one occasion $5 \mathrm{oz}$. of blood were transfused. In the fifth week deterioration became more rapid, and on May 20 a continuous tibial saline drip was started. The next day the child began to get constipated and the abdomen became very distended. The contours of the bowel loops could be seen and high-pitched bowel sounds auscultated. A rectal examination revealed mucus and faeces only.

On May 23 the bowels ceased to act altogether and the child appeared much worse, copious vomits of bright green curds now welling out of the mouth. The abdominal distension had increased still further, and bowel sounds were very noticeable. An enema was given without effect. Intestinal obstruction had now obviously supervened. Continuous infusion of saline was maintained, and an injection of atropine gr. $\frac{1}{200}$ was given intramuscularly. The next day the child appeared even worse. His abdomen was very tense and the skin reddened over the midportion of it. Duodenal suction was started, but owing to the extremely rapid deterioration the child was never fit for operation. He died on the evening of May 25. Over the last thirty-six hours the pulse and respirations were much increased, but the temperature continued approximately normal. The breath sounds were very harsh terminally all over the chest.

Autopsy report. The body was that of an emaciated male infant with transfusion puncture wounds over both tibiae.

Abdominal cavity. The abdomen was greatly distended. On opening the peritoneal cavity fibrinous adhesions were found between the loops of the small bowel, and also between the bowel and the anterior abdominal wall. In addition the whole of the small intestine showed considerable distension, purple discolouration, and loss of sheen, these changes being most marked in the right iliac fossa and particularly in the distal twenty-three centimetres of the ileum. A firm mass could be palpated in the position of the ileocaecal valve. The whole of the large bowel was collapsed. There was a small amount of turbid greenish-yellow fluid in the peritoneal cavity.

THE ENTEROGENOUS CYSTS. The ileocaecal region, together with five centimetres of colon and ten of ileum on either side of it, were detached from the rest of the bowel and carefully dissected. The mass was found to be due to a cystic swelling lying in the ileum just proximal to, and in fact partly adjacent to the ileocaecal valve (fig. 1). It caused a slight bulging outwards of the external surface of the ileum just medial to the caecum and ascending colon and anterior to the terminal portion of the mesentery of the small intestine.

The long axis of the cyst, which was the larger of two contiguous cysts (see below), was directed inferiorly and slightly medially. Its general shape was that of a dumb-bell, the long diameter being $3.75 \mathrm{~cm}$. and the maximum transverse diameters 2.0 and $2.5 \mathrm{~cm}$. The diameter of the neck was $1.5 \mathrm{~cm}$. The two portions of the cyst separated by this neck consisted of a larger (two-thirds) part within the wall of the ileum and a smaller (one-third) portion which extended into the lumen of the bowel (fig. 2). 
Part of the infero-lateral wall of the latter portion formed part of the superior border of the ileocaecal valve, the cyst projecting further into the cavity of the ileum to come into contact with the diagonally opposite wall. The result was that the valve was completely cut off from the rest of the ileum by the cyst.

The wall of the luminal portion was very thin $(0.5 \mathrm{~mm}$.). The external wall of the intramural portion was $2 \mathrm{~mm}$. thick; its lateral aspects were firmly supported by the wall of the ileum. The interior of the cyst was of light grey colour and showed coarse and fine trabeculation on the wall of the intramural part. The lining was in part velvety, in part shiny.

On the infero-lateral aspect of the intramural portion of the above cyst another small slit-like cyst was present, approximately $1 \mathrm{~cm}$. in length and depth and $0.2 \mathrm{~cm}$. in width (fig. 2). The interior was of similar colour and texture to that of the big cyst with which it did not communicate.

The fluid contained within the larger cyst was clear, faintly brown-stained and of low viscosity. Some was removed for analysis before the cyst was fixed in Kaiserling solution. The analysis was kindly carried out by Dr. F. T. G. Prunty, who reported the following findings: $p H \quad 6.9$, total protein 1.13 per cent. with a trace of mucus, sugar $17 \mathrm{mg}$. per cent., cholesterol $14 \mathrm{mg}$. per cent., chloride $\mathbf{4 0 0} \mathrm{mg}$. per cent. as $\mathrm{NaCl}$. No evidence of enzyme activity could be detected (cf. Rea, 1940).

Many shallow ukers were found in the mucous membrane in the ileum for about $30 \mathrm{~cm}$. proximally above the cyst. They had irregular slightly overhanging edges and showed no induration (fig. 1). The vermiform appendix was normal. The liver showed diffuse congestion, and the spleen was rather softer than normal. No gross abnormality was found in other viscera.

Thoracic Cavity. The lower lobe of the right lung showed extensive collapse. The lower lobe of the left lung contained areas of subpleural collapse. Both lungs otherwise were very congested and somewhat firm. There was no abnormality of the heart or thoracic aorta. The thymus was normal.

Microscopical examination. Sections were cut of the cysts and stained with haematoxylin and eosin, haematoxylin and van Gieson's stain, and with mucicarmine for mucin. A section was also cut of one of the ukcers in the ileum proximal to the cyst.

The larger cyst was completely surrounded by smooth muscle, which was continuous with the circular muscular coat of the ileum. The total thickness of muscle was much greater in this area than in the normal bowel on either side. Where the cyst projected into the lumen of the bowel the muscular covering was very thin; at the points of reflection of the bowel on either side, the muscle reached its maximum thickness, and on the peritoneal aspect its width was intermediate. Strands of fibrous connective tissue occurred irregularly within this muscular coat so that in places the cyst appeared to have a muscularis mucosae. For most of the circumference, however, the mucous membrane of the cyst lay directly on the muscular coat. Over a considerable area of the mucous membrane the epithelium had been shed. Where it remains it was of normal intestinal type. The lining cells were tall columnar with clear cytoplasm and basal nuclei. Here and there goblet cells were present. Both these, and many of the lining mucosal cells, stained positively for mucin (fig. 3). The lamina propria was shallow and hypocellular, and contained simple, slightly tortuous tubular glands having epithelium similar to the lining mucosa.

The mucosa of the smaller cyst lying alongside the larger was similar to that of the latter. For about two-thirds of the circumference fibrous connective tissue divided the muscular coat so that the cyst appeared to have a muscularis mucosae over this area (fig. 4).

Section of the uker of the ileum showed that it had penetrated as far as the inner aspect of the circular coat, the base being formed by an exudate consisting of lymphocytes with a few neutrophils and eosinophils. The surrounding tissues were congested and oedematous, and showed infiltration with similar inflammatory cells. There was no evidence of a tuberculous infection.

Other histological changes. The lungs showed congestion, oedema, acute bronchiolitis, bronchopneumonia, emphysema, and subpleural collapse. There was severe venous congestion of the liver.

\section{Comment}

The cysts described in this case are examples of those broadly known as enterogenous (Evans, 1929) and are almost certainly congenital, the results of aberration of normal development of the intestinal canal. Well over fifty cases having these enterogenous cysts have been reported since the original one of Fraenkel in 1882 . They have been shown to exist in many situations, for example, in the wall of the alimentary tract or attached to it or separate from it, in the latter case being usually in the folds of the mesentery. Over 50 per cent. of the reported cysts have been in the region of the ileocaecal valve, though the number in the same position in the ileum, as in this case, is, of course, considerably smaller. Analyses of the case reports and discussion of the modes of development of these cycts have been given more than once (Evans, 1929; Drennen, 1931; Hughes-Jones, 1934; Pachman, 1939), and nothing is to be gained by going into these subjects again.

The cysts described here are like the majority in this region in being intramural (Pachman, 1939). It has been claimed by Dockerty et al. (1939) that such cysts show a faithful reproduction of the layers of the intestinal wall, but this certainly 


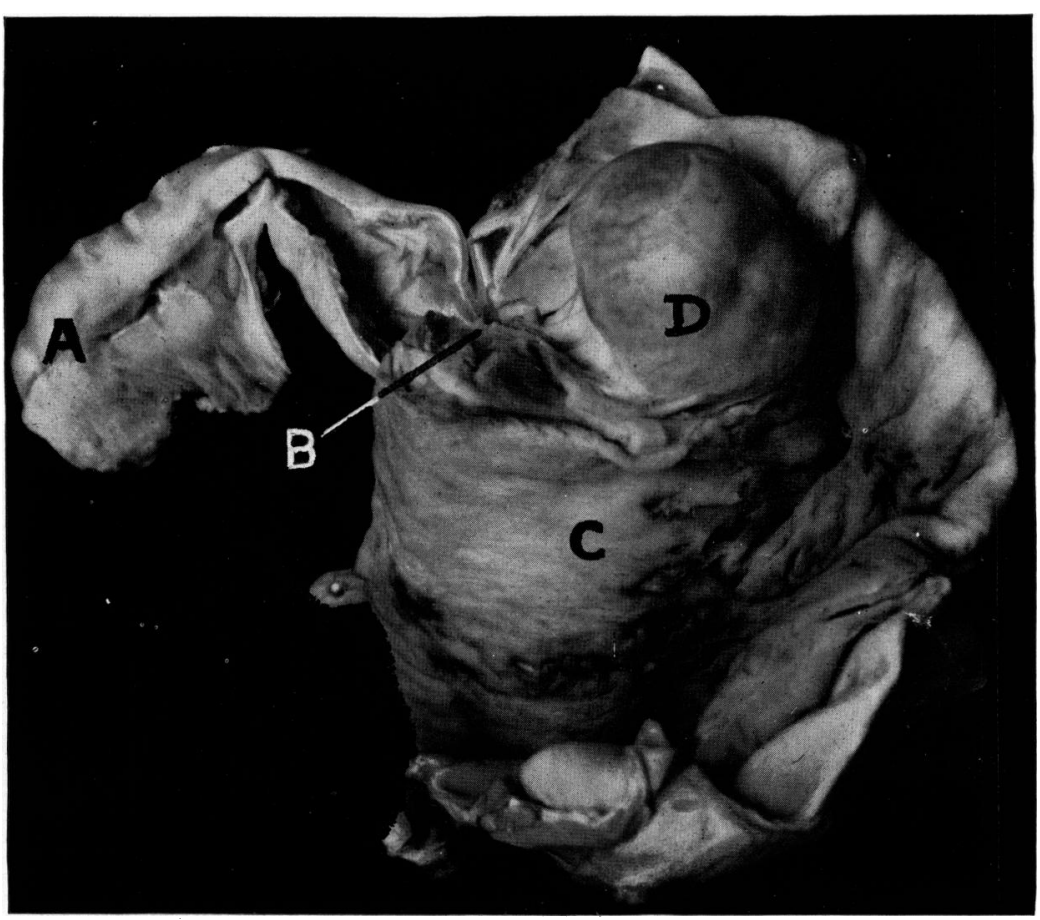

FIG. 1.-(A) colon; (B) ileocaecal valve; (C) ileum showing ulcers on mucosa; (D) cystic swelling.

does not always appear to be so. In the present example the mucous membrane of the larger cyst very frequently lies on the muscular coat without the suspicion of muscularis mucosae or submucosa, and indeed the same state of affairs seems to be shown in the microphotograph of the cyst reported by the authors above. Their case appears from their description and illustrations to be very similar in situation and structure to the one here described.

The extreme thinness of the larger cyst wall where it is covered by the mucous membrane of the ileum, the dumb-bell shape of the cyst, and the comparatively recent onset of the acute intestinal obstruction, suggest that the cyst had enlarged inwards to occlude the lumen of the ileum relatively quickly towards the end. Presumably the starting of feeding soon after birth would have caused an increase in the secretory activity of the cyst epithelium, and it would be when the intra-cystic pressure became greater than the containing pressure of the weakest portion of the wall that the most rapid dilatation of that section of the cyst took place. The presence of mucussecreting cells in the epithelium and mucin in the fluid gave evidence that the epithelium was secreting actively at the time of death.

If any symptoms are produced by cysts in the ileocaecal angle, they are usually, as here, those of intestinal obstruction, and they most frequently appear in the first few months of life. Intussusception occasionally results. Resection of a portion of the bowel to include the cyst is the operation most frequently used, and a high proportion of successes has thereby been reported (Pachman, 1939). In this case, it was misleading and unfortunate that a phase simulating gastro-enteritis occurred four weeks before definite signs of obstruction ensued. The child's general condition was thus weakened and, as has already been stated, when the acute obstruction supervened the progress downhill was so rapid that operation could not at that time be entertained.

\section{Summary}

A clinical and pathological description is given of two enterogenous cysts occurring in the terminal ileum of a male infant. The child died from intestinal obstruction resulting from the expansion of one of them into the lumen of the ileum. Some features of such cysts are briefly discussed.

My thanks are due to Dr. J. Forest Smith for permission to publish this case, and to Mr. A. E. Clark for help with the photographs.

\section{REFERENCES}

Dockerty, M. B., Kennedy, R. L. J., and Waugh, J. M. (1939). Proc. Mayo Clin., 14, 664.

Drennen, E. (1931). Arch. Surg., 22, 106.

Evans, A. (1929). Brit. J. Surg., 17, 34.

Fraenkel, E. (1882). Virch. Arch. path. Anat., 87, 275.

Hughes-Jones, W. E. A. (1934). Brit. J. Surg., 22, 134.

Pachman, D. J. (1939). Amer. J. Dis. Child., 58, 485.

Rea, G. E. (1940). Ann. Surg., 112, 300. 


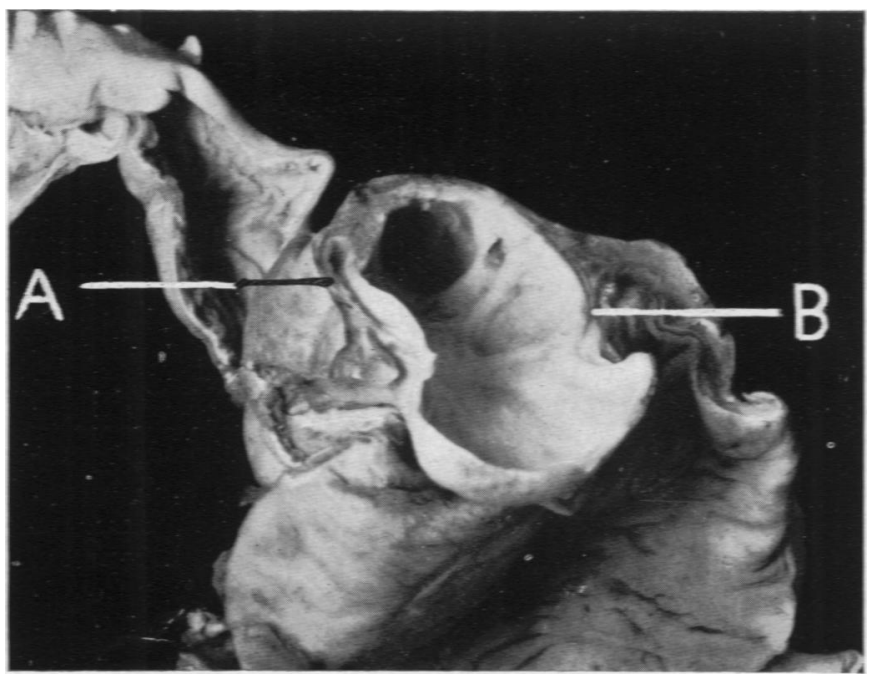

Fig. 2.-(A) smaller cyst; (B) larger cyst.

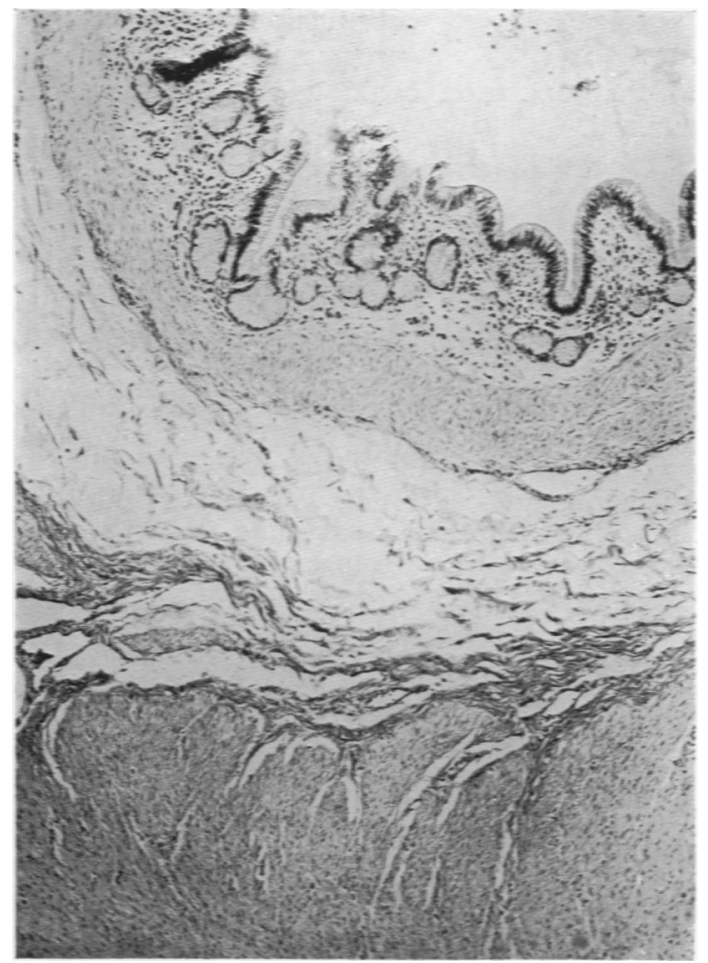

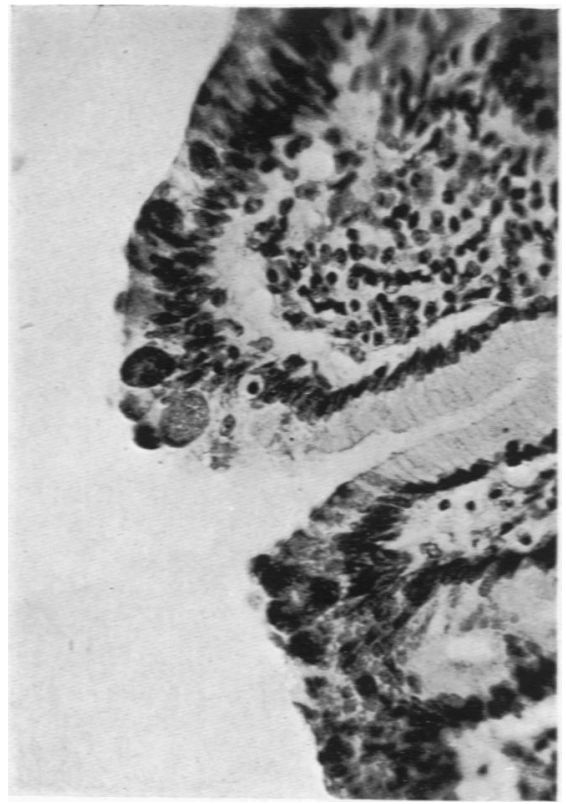

Fig. 3. - Part of the lining epithelium of the larger cyst stained with mucicarmine, showing positive reaction in some of the cells. $(\times 215$. $)$

FIG. 4.-Part of the wall of the smaller cyst. $(\times 45$. 
Fig. 1.-Posterior of gastric mucosa, showing two large active ukcers and two healing and scarred ukcers. (Natural size.)
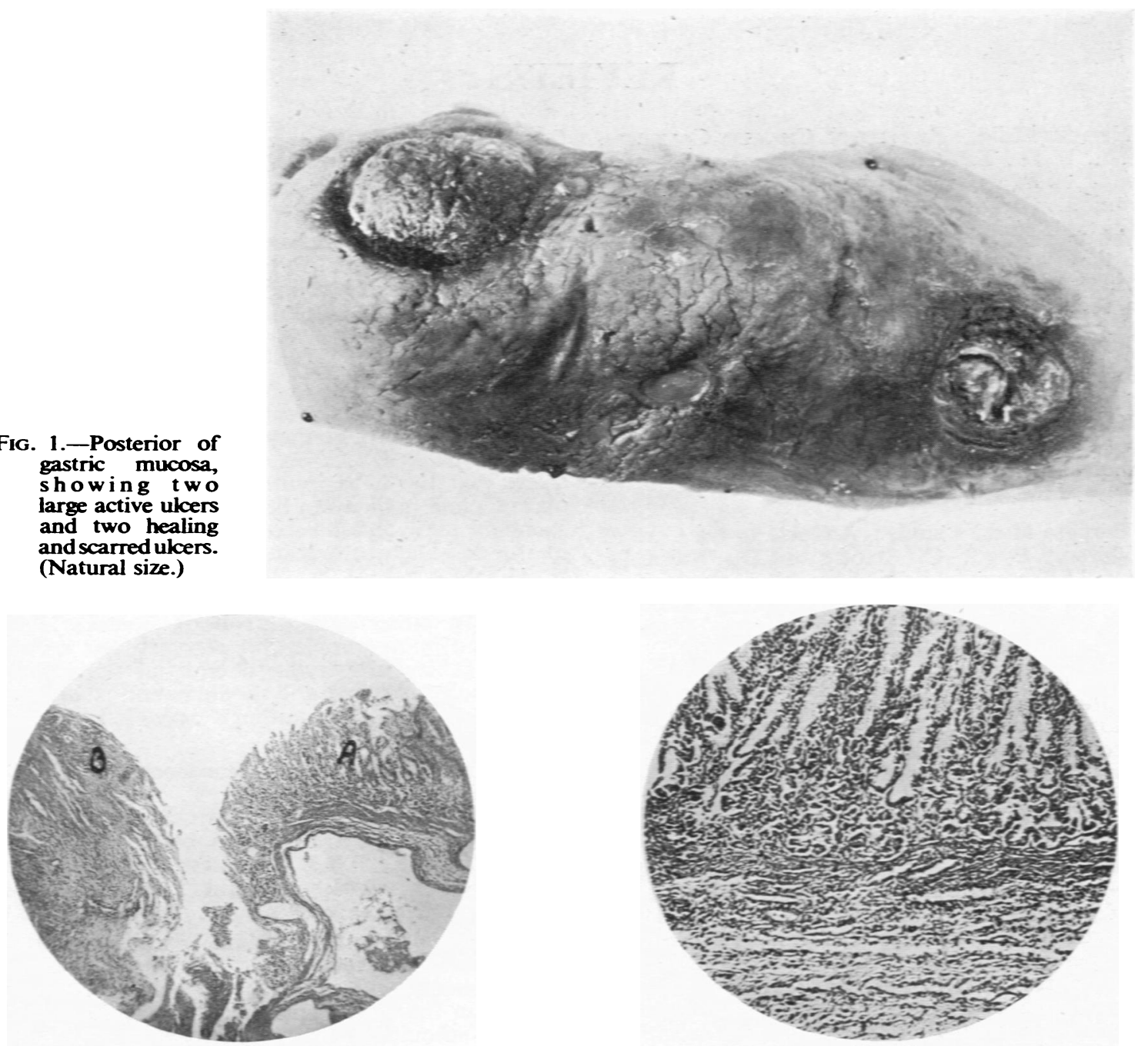

FIG. 2.

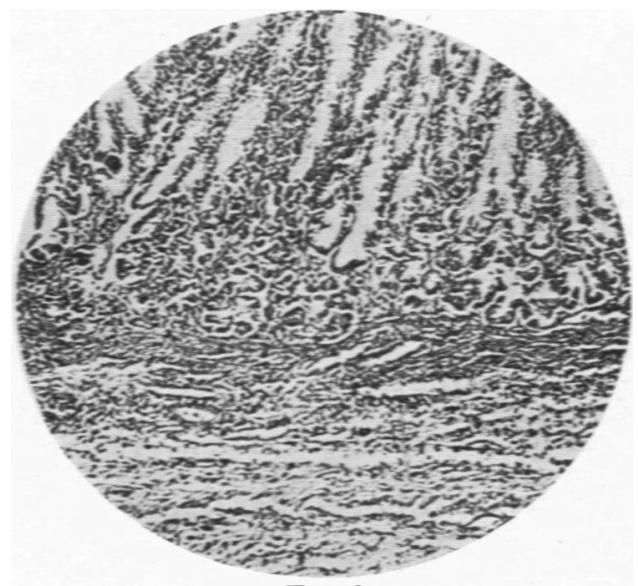

FIG. 3.

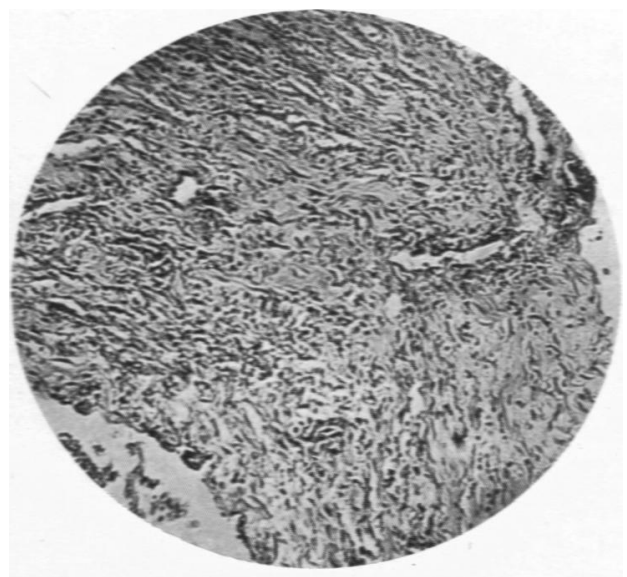

FIG. 2.- Low-power microphotograph showing normal mucosa and edge of acute uker. ( $\times$ 30.)

Fig. 3.-High-power microphotograph of A, showing small-celled infiltration of the submucosa and the muscle layer. $(\times 90$.

Fig. 4.-High-power microphotograph of $B$, showing fibrous tissue and small-celled infiltration of the uker base. $(x$ 90.)

FIG. 4. 